\title{
DEMAND AND SUPPLY ANALYSIS ON MANUFACTURING OF CEMENT FOR MONSOON PERIODS USING DVORAK TECHNIQUE
}

\author{
K. RAJESH, K. R. SEKAR, V. RAMASWAMY, K. KANNAN \& R. MANIKANDAN \\ School of Computing, Srinivasa Ramanujan Center Sastra University, India
}

\begin{abstract}
In India cements manufacturing industries are the second largest industry, giving more market share and in the increasing trend. Infrastructures and investments in the construction of buildings in India are growing exponentially. Indian government has boosted the growth of cement sales and industries to increase the economy growth. During non monsoon seasons, the growth becomes doubled compared with the monsoon period between AprilJune 2016, Deccan cement has got 80.70 \%sales and Heidelberg cement has got the low sales $34.22 \%$ sales. In $2016-$ 2017 increased cement price in North $-10 \%$, centralregions-7\%. At that time price of the cement were slashed down to Rs 320 per bag from $R s$ 400-420 per bag. In the monsoon period the production of the cement has increased, so that to meet their demands in the non monsoon periods. Cyclone tropical monsoon has got a greater impact in the manufacturing of cement. To measure the intensity of the cyclone during the monsoon season has proposed using Hyper graph, Dvorak Technique and Cyclone images.

KEYWORDS: Monsoon, Infrastructures, Constructions, Dvorak Technique Tropical Cyclone \& Intensity
\end{abstract}

Received: Oct 10, 2017; Accepted: Oct 23 2017; Published: Nov 08, 2017; Paper Id.: IJMPERDDEC201720

\section{INTRODUCTION}

The cement industry concentrates more on fiber cement siding which is more fascinating and durability is very high. All types of quality of service (QoS), have been implemented, in the above said cement concrete. Some of the buildings still constructed during the monsoon season because to get rigid in that period. In the previous year's sales are $2012-\rightarrow 230$ million tones, 2013 $\rightarrow 248.23,2014 \rightarrow \quad 255.83, \quad 2015 \rightarrow$ $270.04,2016 \rightarrow 283.46$ and $2017 \rightarrow 279.81$ million tones up to July. The expected sales are up to 420 million tones. Compound annual grade rate from the external affair ministry has reported the growth rate 9.7 percent. In the year 2020 their expected sales is 550 million tones. Before and after the demonization the GDP becomes reduced. In Jan $2016 \rightarrow 9.2$ is the highest GDP and July $2017 \rightarrow 5.7$ is the lowest GDP. The Indian economy growth depends on the different industrial sectors one among them is cement manufacturing. The Pre monsoon and the post monsoon literally have got an impact in the cement manufacturing industries. The cyclone impact reduces cement price and manufacturing. But now in India during the monsoon period the Government boosted manufacturing cement to the extent.

Climatology refers to weather history over a location or region and involves study of characteristics of weather in a particular region. The process involves the analysis of metereological parameters, such as temperature, pressure and wind and correlating each other. Rainfall is an important weather parameter. Rainfall prediction is one of the daunting tasks [1] in current environment, which requires modern type of simulation and modeling for high accuracy. Empirical and dynamic are two different approaches, for predicting 
rainfall. Empirical model helps in the analysis of historical data, by providing relationship over atmospheric variables, around the world. Dynamic model makes use of mathematical equations for predictions. Though, several approaches are available, unprecedented weather conditions, such as exceptionally heavy rainfall etc., makes rainfall prediction a really challenging task.

Lots of research work is being carried out, to predict rainfall early so as to avert natural calamity. Another most disastrous natural calamity is cyclone which causes more damage to human environment [2]. Cyclone is called by different names, such as hurricane in Atlantic and eastern pacific, whereas in western pacific, it is called typhoons [3]. Cyclone affects Indian coasts also. Though, tropical cyclone has got basic features, it has regional specialities also. $[4,5,6,7]$

Satellite pictures are handy tools for the study of cyclones. Satellites can continuously monitor the cyclone movements and stages. Lots of research works are going on related to cyclone intensity level computation and prediction. Accurate detection is difficult as the parts of cloud can be easily confused with some form o $\mathrm{f}$ ice or snow covered the region.[8]. Dvorak is one of the most important techniques which was developed during the later part of 1970s [9]. Some advancements were incorporated into the technique and the technique was renamed as "Advanced Dvora $\mathrm{K}$ Technique". Intensity of cyclone was predicted by comparing various bands around cyclone center. The complexity is in terms of computation for processing each pixel of satellite pictures. Various methodologies were adopted to reduce time complexity . One such methodology is hyper graph technique, where no pixels are left unprocessed.

Generally, graphs are used to connect two nodes whereas hyper graphs are used to connect two or more nodes. In that respect, hyper graph can also be called family of sets which is derived from one Universal set.

A simple hypergraph with an ordered couple $\mathrm{H}=(\mathrm{V}, \mathrm{E})$, where $\mathrm{V}$ is called as non empty finite set and $\mathrm{E}$ is called as non empty subsets of V [10]. Hypergraph has got some types, such as sub hypergraph, partial hypergraph and section hypergraph. A sub hyper graph is obtained, by removing some vertices, whereas a partial hyper graph is obtained by removing some edges.

Tropical cyclones create problems in coastal region. Predicting the tropical cyclone system with higher accuracy is a major challenge. Research communities are working hard in this area to enhance the level of prediction, using latest technologies.

\section{Dvorak Technique}

Satellite images have good resolution, compared to ground images. Sophisticated sensor based satellite images mitigate the issue of distortion in images. The advent of Advanced Dvorak technique (ADT), improves the observations in the existing one by incorporating features, such as statistical and empirical analysis. Advanced Dvorak technique is based on the operational concepts of Dvorak technique, which was developed by Vern Dvorak during 1970s. ADT includes the combination of Objective Dvorak technique (ODT) and advanced Objective Dvorak technique. The incorporation of Dvorak technique into hyper graph provides more finite classification results, in addition to less computation time for the processing of images.

\section{Ideology Behind Dvorak}

Dvorak technique evolution began during 1970s. [9] Modifications on techniques, took place during later stages. Dvorak technique lies primarily on four other physical parameters - two from kinematics and two from thermodynamics to 
correlate cloud patterns with its tropical cyclone intensities. According to Dvorak, when the cloud features are measured in clear cut manner, the intensity can be in desired format.

\section{Evolution of the Method}

In early stages, National oceanographic and atmospheric administration provided satellite data which helped in developing a technique for measuring tropical cyclone intensity with the help of Geo Stationary satellite data. The information about spectra received from current VIS/IR based images proved to be effective in providing advancement in Dvorak Technique. Vern Dvorak also proposed that, the level of accuracy increases, when microwave images are used. The methodology of finding relationship with cloud signatures and brightness temperature, leads to values such as tropical cyclone intensity. This methodology is named as Dvorak technique.

Cyclone intensity is related to minimum pressure, maximum wind speed and to surface or cloud temperature. (Refrance-figure 1).

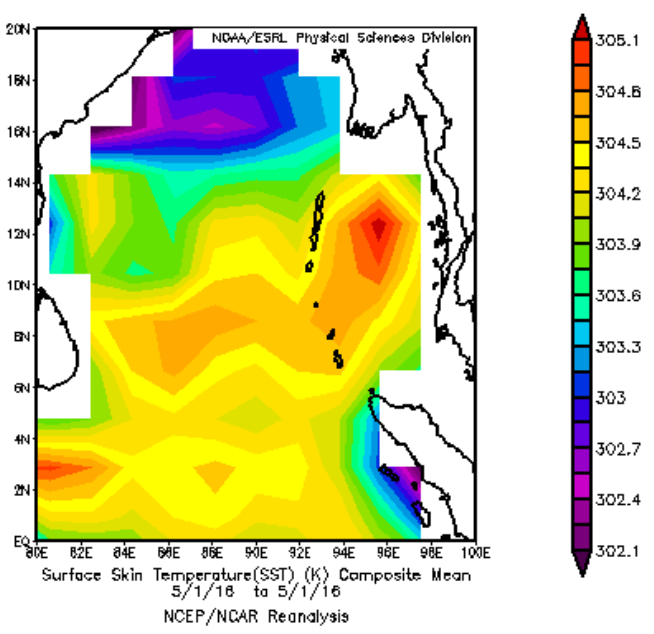

Figure 1: The Correlation Between Surface Temperature and Wind Speed

After receiving images from satellite, these images are compared with the various pattern types such as Shear Pattern, Curved Band Pattern, Eye Pattern, Central Dense Overcast and Embedded center Pattern. Using the schemes that are available, the difference between the temperature of warm eye and surrounding cold cloud tops is derived. If the difference is larger, then the estimation of intensity is more accurate. 


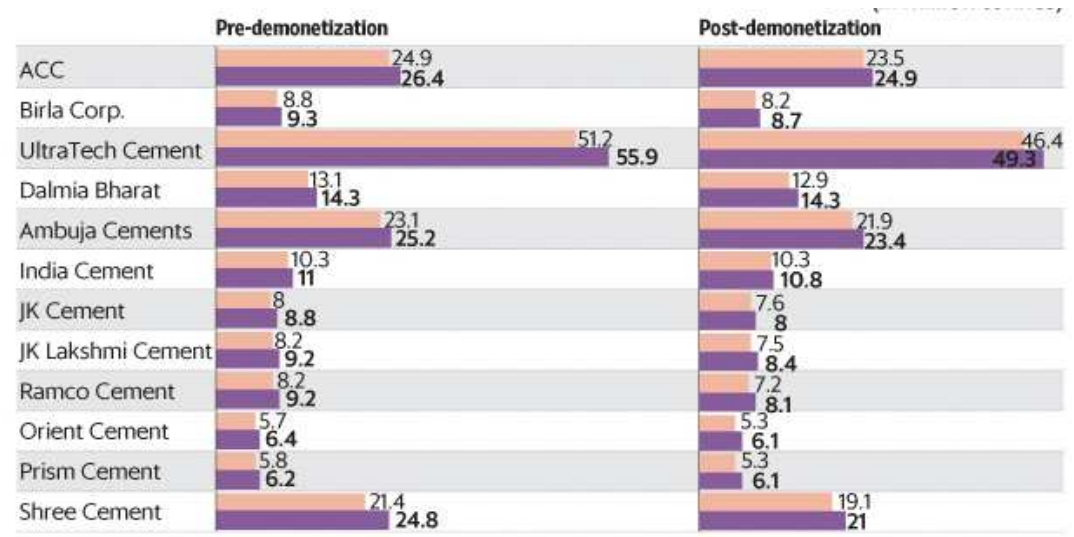

Source: Motilal Oswal Securities

Figure 2: Cement Growth Observed Before Demonetization and Post Demonetization

\section{Technique}

Dvorak Technique (DVKT) assigns T numbers, ranging from 1 to 8 where the lowest number denotes the initial stage of storm.

This process is said to be dynamic in nature. For every 15 minutes or 30 minutes, changes in the pattern type may occur. This is found to be helpful, in recognizing the current updating status of storm. At the same time, wind and surface temperature with respect to the region should also be taken into consideration. Objective Dvorak Technique (ODT) is an algorithm which follows similar kinds of techniques used in Dvorak but slightly on par in terms of estimation under minimum sea level pressure. Further, the accuracy level is enhanced when compared to Dvorak technique under different conditions.

Advanced Operational Dvorak Technique (AODT) has enabled improvements in terms of accuracy of predictions. In this technique, few additional DT constraints have been incorporated which makes classification accurate. These additional DT constraints along with AODT algorithm have resulted in significant improvements in the classification and prediction levels. AODT has been developed using normal program code which is platform dependant where the ODT users could run under MCIDAS Environment for navigating and for some calibration process. MCIDAS, is called as "Man computer Interactive Data Access System", which is a tool used forecasting the weather, which is developed at the University of Wisconsin-Madison in the 1970s which is used to run in different platforms,

AODT algorithm has been further incorporated within the Library of Objective Dvorak Technique code which makes the system easier to operate or process the images irrespective of platforms. The restructured code can also be implemented in non -MCIDAS system also. Different images from various satellites and fused together with advanced sensors increase the accuracy level of prediction.

The approach behind Dvorak technique is diagrammatically represented in figure 2 :

\section{Incorporation of Hyper Graph}

The cyclone strength is manifested by using $\mathrm{T}$ values which are tropical intensity values. These values might change from time to time, by comparing the available patterns such as Curved band pattern, Shear pattern, central dense overcast and eye pattern with the satellite images received, classifications based on the interpretation of satellite images can be carried out in an effective manner. 
We intend to use hyper graph technique, for classification of pixels into groups. The images that are received from satellite, will be processed using the above technique with minimal time, but with maximum efficiency. Pixels with similar kinds of intensities are grouped together, to form a class.

\section{Existing technique}

In the existing techniques for the interpretation of satellite image of the cyclone field similar kinds of neighborhood pixels, with same intensity values are mapped one at a time which is a time consuming process. To overcome this drawback, we propose hyper graph technique. More than two edges can be connected together to form a group. Edges of a particular images are connected together to form as a boundary. This connecting process is called as contour [11].

\section{Proposed Technique}

When a satellite image of cyclone is received, it is subjected to an algorithm called cyclone intensity calculation using hyper graph. The main feature of this algorithm is that when we retrieve a pattern used for comparison, the intensity of the cyclone can be estimated. In this algorithm, the linking of similar kinds of intensities of neighborhood pixels is recognized by hyper graph tool. When the neighborhood pixels, whose intensities are similar, are connected together, some form of pattern may appear. The Tropical cyclone number, which indicates the intensity of cyclone at any time, can be estimated. Based on the bands, the corresponding cyclone numbers are derived. Wind speed and pressure that occur at that particular time should also be provided as input. The wind speed with pressure is correlated with the intensity values from which the grade of storm can be determined [12].

\section{Algorithm Explanation}

- Satellite pictures received are the inputs to our system. These images are stored and processed using hyper graph.

- The intensities of similar kinds of pixels are grouped together which generally yields some kind of structure. This structure is then compared with the already developed pattern structure and the intensity values are computed.

- Based upon the standards for the $\mathrm{T}$ numbers which is already available, $\mathrm{T}$ numbers are provided as inputs. Depending on conditions such as "pattern is curved", "deep curved" etc. corresponding T number is allocated.

- The wind speed and temperature at that time should be correlated with the pattern structure formed.

- Identify the mean pressure drop at that location. Subsequently, recognize the final estimation of the grade of cyclone. 
The Adopted Methodology

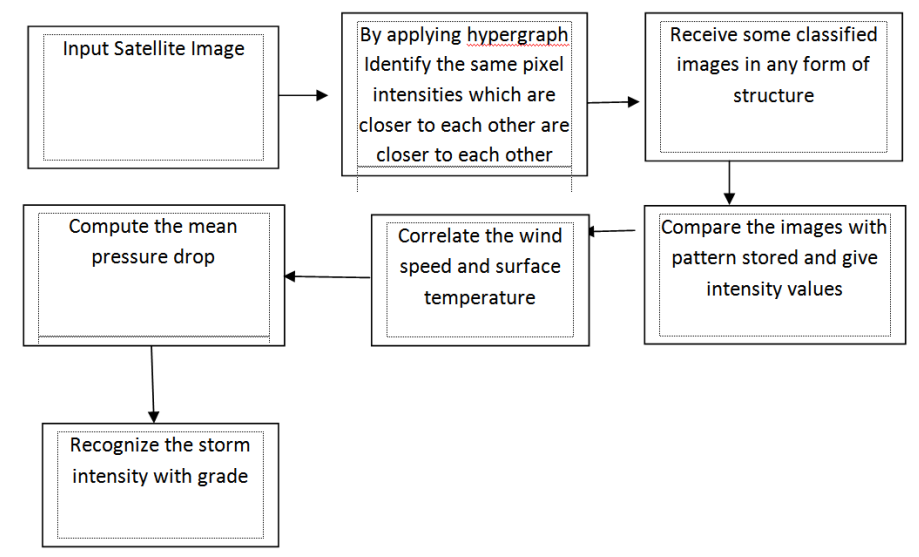

Figure 3: Adopted Methodology

\section{CONCLUSIONS}

Cement manufacturing industries depends on government policies and principles. Infrastructures and constructions are growing in India to become the world power nation. Pre demonetization and post monetization affects the cement industries growth. Pre monsoon and post monsoon has got its own impact in the industrial growth. The government should take a remedial measure to stop the declining growth of the nation in all the seasons. For that heavy expertise and methodologies are needed to fulfill the requirements in the coming years. During the past two to three decades, Dvorak's methodologies and applications in satellite images in terms of forecast analysis proved to be very effective. Even though misconceptions based on distorted images are possible, Dvorak technique has been found to be effective in estimating cyclone intensity. Our proposed methodology is expected to address the problem of misconceptions by using hyper graph technique. Since, the processing is being carried out for Infrared, visible and Ultra Violet images, hyper spectral images and Microwave images can also be considered for better classification. The intensity of images received from satellites can be improved further by using IR or microwave images. To improve classification further, fuzzy based hyper graph technique can be thought of.

\section{ACKNOWLEDGEMENT}

The authors would like to express their sincere thanks to the following experts for their valuable suggestions and the fruitful discussions the authors had with them.

- Dr. Balachandran Director of Regional Metereological center Chennai and

- Dr. T. R. Sivaramakrishnan Director,(Retd) Metereological Department and former Dean(Research) SASTRA University and

- Dr. S. R. Ramanan, Scientist-E(Retired) of India Metereological Department, Chennai.

\section{REFERENCES}

1. Deepak Ranjan Nayak, Amitav Mahapatra and Pranati Mishra " A Survey on Rainfall Prediction using Artificial Neural Network” International Journal of Computer Applications (0975-8887) Volume 72- No.16, June 2013.

2. Chandran Roy, Rita Kovordányi , "Cyclone Track Forecasting Based on Satellite ImagesUsing Artificial Neural Networks" ISPRS journal of photogrammetry and remote sensing (Print), (64), 6, 513-521. 
3. Edward N. Rappaport, James L Franklin, Lixion A. Avila , "Advances and Challenges at the National Hurricane Center" NOAA/National Weather Service/National Hurricane Center, Miami, Florida.

4. Christopher velden, Bruce Harper,"The Dvorak Tropical Cyclone Intensity Estimation Technique”, American Metereological Society, September 2006

5. A K Mukherjee and T R Sivaramakrishnan "Surface wind and sea waves in a hurricane field" Nature Vol 267(1977) P236

6. G S Ganesan, A Muthuchami \& E R Sukumar. Mausam “Formation of tropical cyclones in the Bay of Bengal.” 45, 3 (1994) $P 235$

7. KN Rao and S Jayaraman “Frequency of depressions and cyclones.” Indian J Met Geophys. 9 (1958) P233

8. Dinu john Dr. B. B. Meshram " A Data mining approach for Monsoon prediction using Satellite image data” International Journal of Computer Science \& Communication Networks, Vol 2(3), 421-424

9. Vernon F. Dvorak "Tropical Cyclone Intensity Analysis and Forecasting from satellite Imagery” , Application group, National Environmental Satellite Service, NOAA, Washington .

10. K. Rajesh D. Sarala, V. Venkataraman and K. Kannan "Hypergraph based algorithm for segmentation of weather satellite imagery "Indian journal of science and technology, vol9(36), september 2016.

11. D. Poopathy Dr.

12. R. Manicka Chezian "Identification and Classification of Cloud-dense areas in Infrared Weather Imagery using Intensity Contours"International Journal of Engineering Research and General Science Volume 2, Issue 5, August-September, 2014

13. Jeff Callagan and Roger K. Smith "The relationship between maximum surface wind speeds and central pressure in tropical cyclones” Aust.Met.Mag.47 (1998) 191-202 
